\title{
Demonstration of dryland species on 90 east coast North Island farms
}

\author{
G.D. MILNE ${ }^{1}$, S.C. MOLONEY ${ }^{1}$ and D.R. SMITH ${ }^{2}$ \\ ${ }^{I}$ Grassline ${ }^{\circledR}$, AgResearch Grasslands, PB 11008. Palmerston N orth \\ ${ }^{2} \mathrm{AgResearch}, \mathrm{H}$ aw kes Bay Research Centre, PO Box 85, Hastings
}

\begin{abstract}
A drought pasture demonstration programme was established on the east coast of the North Island, between 1990 and 1992. Dryland pasture species were established on 1500 ha, on 91 farms, to encourage other farmers to use them rather than relying totally on perennial ryegrass. $97 \%$ of pastures were established successfully, proving to farmers that dryland pasture species can be established reliably. As well as establishing pastures after cultivation, it was also proven that these species can be reliably established by direct drilling, or by oversowing onto hill country, using techniques developed in this programme. Some farmers monitored the amount of grazing obtained from the new pastures, and found that on average they received $112 \%$ more grazing annually than resident pastures, the largest increases occurring in summer. Many farmers also reported better animal growth rates on the new pastures, especially in summer and autumn. Monitoring of species presence in tiller cores has shown the sown species to be persisting well to date (Nov 1992), with the exceptions of tall fescue and grazing brome when sown onto hill country. The programme reinforced factors important in the establishment and grazing management of dryland pastures. The programme has brought about a noticeable change in attitude to dryland species, and seed sales have increased markedly while ryegrass sales have decreased.
\end{abstract}

Keywords: Cichorium intybus, Dactylis glomerata, drought, Festuca arundinacea, demonstration, dryland pasture establishment

\section{Introduction}

The east coast regions of the North Island suffered a severe drought in the summer and autumn of $1988 / 89$. Farmers were forced to sell finishing stock as stores, sell some of their capital stock, and buy in supplementary feed or grazing.

Before 1989, pastures in the region were almost exclusively sown in perennial ryegrass and white clover. Several pasture species (tall fescue, cocksfoot, phalaris, lucerne, chicory) had been developed by DSIR Grasslands in the 1970s, which had been proven to grow longer into droughts and recover better than ryegrass. DSIR Grasslands scientists were concerned that these "dryland" species were not being used by farmers, despite being available for 5-10 years. It was felt that farmer reliance on ryegrass based pastures was accentuating the problems occurring in droughts.

A Drought Pasture Demonstration Programme was set up successfully in North Otago and South Canterbury in 1989. This was already proving effective in encouraging the use of dryland species (Milne \& Fraser 1990).

An application was accepted for DSIR Grasslands to run a similar programme in the North Island, funded through the Government's Drought Relief Package.

The purpose of the programme was to encourage the use of dryland pasture species. Farmers and consultants had a partial awareness of the species, but except for a few, did not have confidence in their benefits, cost effectiveness, establishment and management needs, and risks. By establishing full paddock size pastures on typical farms spread evenly through the regions, it was hoped farmers would pick up that confidence by seeing them on a farm similar to their own. The intention was not to totally replace ryegrass in these regions, but to ensure a more balanced use of dryland species and ryegrass.

\section{Methods}

The aim of the programme was to establish 1500 ha of pasture with dryland pasture species, on farms geographically spread through the east coast regions.

Applications were called for, and farms were selected by local committees in the Wairarapa, Southern Hawkes Bay, Hawkes Bay and Gisbome. Committees consisted of Federated Farmers, MAFTechnology and Rural Trust representatives. A total of 91 farms were selected that could demonstrate new pastures well, and to ensure a coverage of different farm types. A maximum area of 20 ha was sown on each farm. $97 \%$ of farms ran sheep and beef cattle, and 3\% dairying (20\% of the Wairarapa farms were dairying).

Farms were visited in 1990 by specialist pasture advisers from Grassline ${ }^{\circledR}$, to select the appropriate seed mix for each paddock and farm, and inform farmers of establishment and management requirements. Farms were visited shortly after establishment to advise on early management, and most farms received further 
visits. Field days were held on farms to display pastures and transfer information on establishment and management,

As the programme was approved late in autumn 1990, only 142 ha were sown in that year. A further 14 ha were sown in spring 1990, mainly chicory (Cichorium intybus) pastures. Most sowings (1186 ha) occurred in autumn 199 1, but dry weather forced the postponement of 25 ha to that spring, and 160 ha to autumn 1992. A total of 1527 ha were sown.

The main grass species used were tall fescue (Festuca arundinacea, cvs Grasslands Roa and AU Triumph), followed by cocksfoot (Dactylis glomerata, Grasslands Wana, Grasslands Kara and Saborto), phalaris (Phalaris aquatica, Grasslands Maru) and grazing brome (Bromus stamineus, Grasslands Gala) (Figure 1). Species mixtures were designed to fit the needs of each farm system and soil type. Tall fescue was used on sites that could be drilled, with moderate to high soil fertility, and moderate to high waterholding capacity, Cocksfoot and phalaris were used in mixtures with tall fescue, or without tall fescue in harsh sites.

Figure 1 Grass species used, based on tonnages.

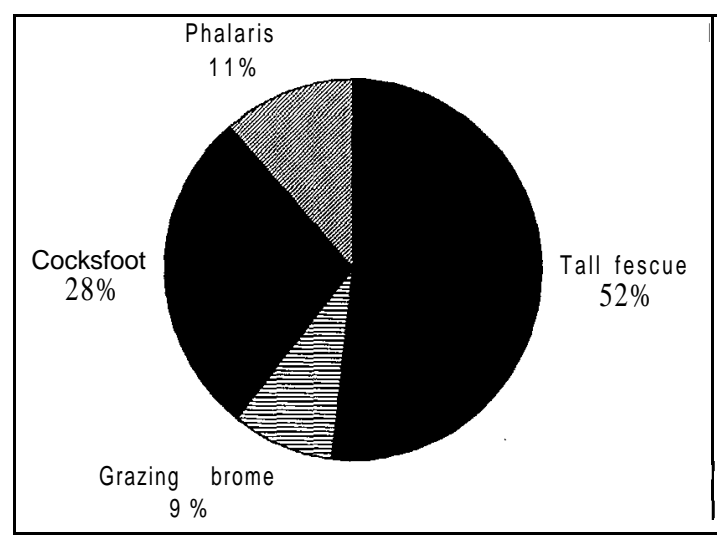

The main legume species used was white clover (Trifolium repens, Grasslands Tahora and Kopu), followed by red clover (Trifolium pratense, Grasslands Colenso, Pawera and Turoa) and subterranean clover (Trifolium subterraneum, Woogenellup). $400 \mathrm{~kg}$ of Grasslands Puna chicory was sown (Figure 2), predominantly with clover only, or mixed with grasses and clovers.

Sixty percent of the area was established after full cultivation of the soil, usually after a greenfeed or cereal crop (Figure 3). Seed was sown using a roller-drill system (Moloney \& Milne 1993). Medium hill country prone to erosion when cultivated was direct drilled, a total of $20 \%$ of the
Figure 2 Legume and herb species used, based on tonnages.

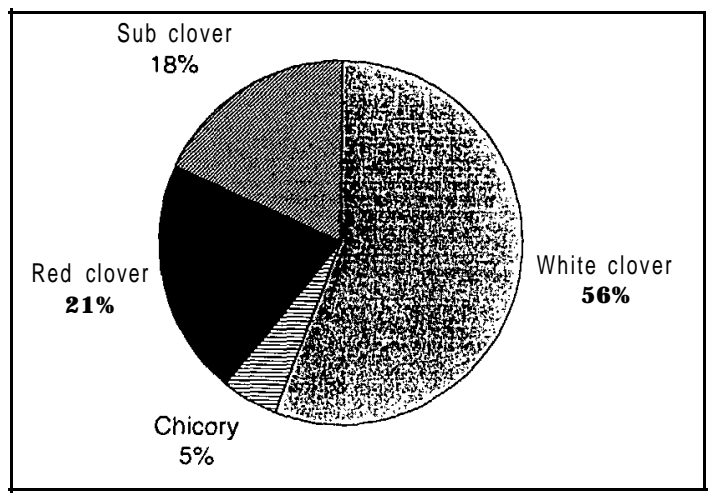

Figure 3 Sowing methods used, based on land area.

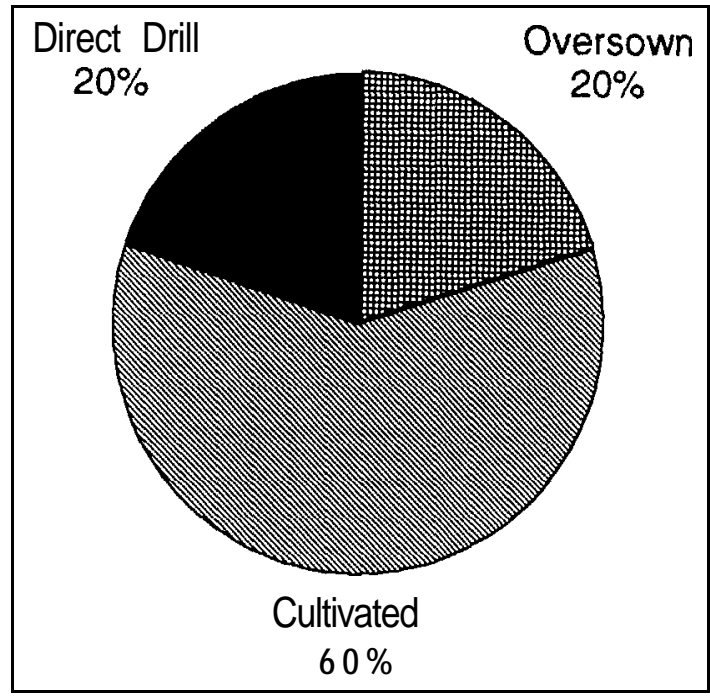

area. A "spray fallow system" was used on most sites, with existing pastures sprayed November and resprayed and drilled in early March. Most directdrilled sites were sown with the Massey University "Bioblade" drill, with insecticide (e.g. $5 \mathrm{~kg} / \mathrm{ha}$ phorate), and slug bait where needed.

Of the area selected, 20\% was steep hill country as local Federated Farmers members wanted options for establishing dryland species on this country to be demonstrated. Sites were desiccated with glyphosate in late autumn, stock forced to tread soil, seed and fertiliser sown, then stock used to tramp seed, and slug or cricket bait applied if needed. The main species used for oversowing were cocksfoot, phalaris, white and subterranean clover. Cocksfoot seed was lime coated to aid spreading by the helicopter, and all legume seed inoculated and lime coated. 
All pastures were sown with $125 \mathrm{~kg} / \mathrm{ha}$ Cropmaster 20 (N:P:K = 20:10:10), with sowings in early March. Average Olsen phosphate level was 15 , with a range of $5-32$.

Rainfall at Napier was higher than the 30-year average for 11 of the 24 months from April 1991 to March 1993 (Figure 8). Heavy rain in April (over 125 $\mathrm{mm}$ in 24 hours) caused establishment problems with seed being washed off slopes, and deep-sown seed rotting before germination.

Where needed, pastures were sprayed after establishment with 4-6 litres/ha MCPB in early winter to reduce annual thistle establishment.

MAF Technology research staff began agronomic measurements on selected sites in the Hawkes Bay and Gisbome regions in November 1991. Seedling densities and sowing depths were first recorded in July 1991, followed by presence of species in tiller core plugs taken in November in 1992 and 1993.

Farmers were asked to keep records of grazing days and pre- and post-grazing heights on new pasture, and some resident pastures as controls. These records were collected in April 1993 and analysed by B.M. Butler using the "GRAZE" software.

\section{Results}

Three percent of the pastures failed to establish, and reverted back to resident species within one year, or were sown again. The success rate of $97 \%$ is high for any pasture type on such a large scale. There was no difference in the proportion of pastures that failed to establish between the three sowing methods, although seedling densities of sown species were highest for cultivation, followed by direct drilling and then oversowing.

Seedling counts of autumn 1991 sown pastures in Hawkes Bay and Gisbome, taken in spring 1991, showed differences in plant emergence rates for the three different sowing methods used (Figure 4) (Smith et al. 1993). Emergence rates were highest for sowing after cultivation, followed by direct drilling and oversowing.

Differences in actual seedling densities between sowing methods were not as pronounced owing to the use of higher seeding rates when oversowing (Figure 5), and by November of the year of establishment, direct-drilled and oversown paddocks had similar plant densities to cultivated paddocks.

Clover seedling densities did not follow the same trend as for grass seedlings. Clover densities were highest for cultivation, followed by oversowing and then direct drilling. The reason for poor clover densities from direct drilling appeared to be the average seeding depth of $26 \mathrm{~mm}$, compared with oversowing of $5 \mathrm{~mm}$,
Figure 4 Seedling emergence rates for sites measured in Hawkes Bay and Gisbome, July 1991.

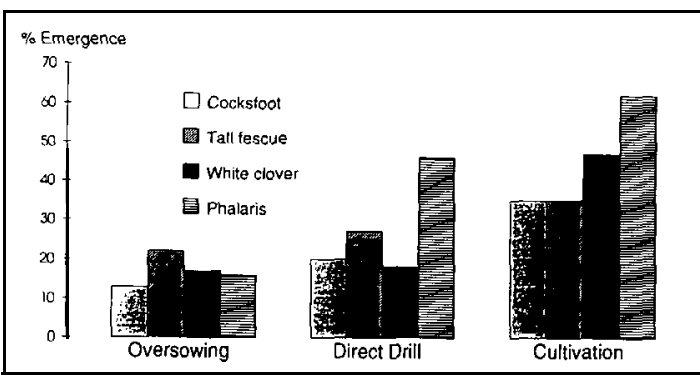

Figure 5 Seedling populations for sites measured in Hawkes Bay and Gisbome, July 1991.

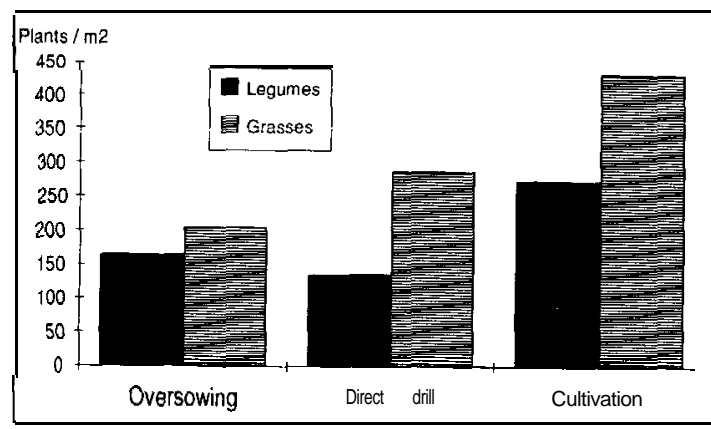

Figure 6 presence of species in tiller cores, measured Nov 1991 and Nov 1992.

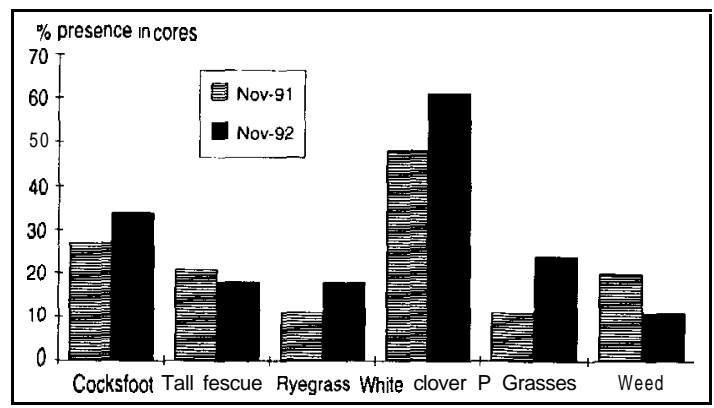

and cultivation $10 \mathrm{~mm}$. However, by November 1991 tiller cores indicated no significant difference between the methods (Smith et al. 1993).

The two tiller core measurements taken indicated a trend for an increasing presence of cocksfoot, resident perennial grasses, white clover, and a decrease in weed presence (Figure 6) (Smith et al. 1993). The proportion of tall fescue in mixed pastures decreased at the expense of cocksfoot and other grasses. In paddocks where Kara cocksfoot was used instead of Wana, however, tall fescue maintained a constant \% occurrence and the presence of cocksfoot declined. 
Paddock grazing day records were collected from 34 of the 91 farmers, and of these 16 kept adequate records of control (resident) pastures. Farmers that did not submit records either forgot to take them or found the way they were grazed made recording too difficult or inaccurate, Analysis of the 16 farms that collected adequate records, showed the paddocks sown carried an average of $112 \%$ more stock unit equivalents annually from sowing to autumn 1993, compared with resident controls (average su grazing days per ha of 12.85 annually and 10.09 in winter) (Figure 7). The extra production was highest during summer months $(+130 \%)$, followed by autumn (+ $114 \%)$, spring $(+105 \%)$ and winter $(+101 \%)$.

\section{Discussion}

The programme demonstrated that dryland pastures could be reliably established by many farmers in difficult climatic conditions. It also proved and publicised the benefits of dryland species, even in relatively moist seasons. The use of dryland species in the regions has increased significantly since the programme began. Records in Waipukurau show a marked increase in tall fescue and chicory seed sales, and a decrease in perennial ryegrass sales since the programme began (B. Smales pers. comm.).

As well as transferring information on dryland pastures to farmers, the programme also reinforced important factors in their successful use.

Critical establishment factors were: paddock preparation; effective elimination of existing weeds and weed seed; early autumn sowing dates; shallow seeding depth (less than $15 \mathrm{~mm}$ ); soil nitrogen fertility; fertiliser applications after sowing; effective post emergence weed control; pest identification and control; and early grazing management.

Time of sowing was crucial to the long- and shortterm production of the pastures. Some pastures sown on 25 February 1991 were grazed three times before August. Others sown in late March were not grazed until September. It appeared that for every week that sowings were delayed after the end of February, first grazings were delayed by one month. Late-sown pastures were more susceptible to weed competition, affecting the final population of sown species, and sometimes their persistence.

Some farmers felt early-March sowing was impossible owing to the commonly dry soils at that time. Other farmers, however, showed that if paddocks were prepared early and fallowed for 1-4 months, seedbed moisture was adequate for rapid pasture establishment despite dry conditions at sowing. Even farmers who had not fallowed paddocks had better
Figure 7 Average stock unit grazing days per ha, for control and new pastures (dryland species).

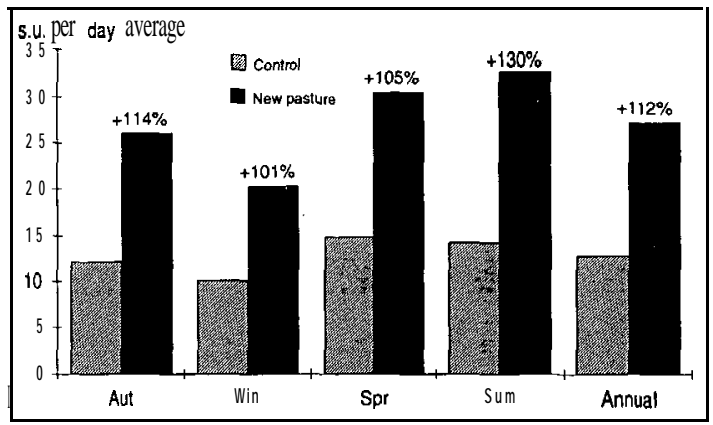

Figure 8 Rainfall at Waipukurau compared with 30-year average.

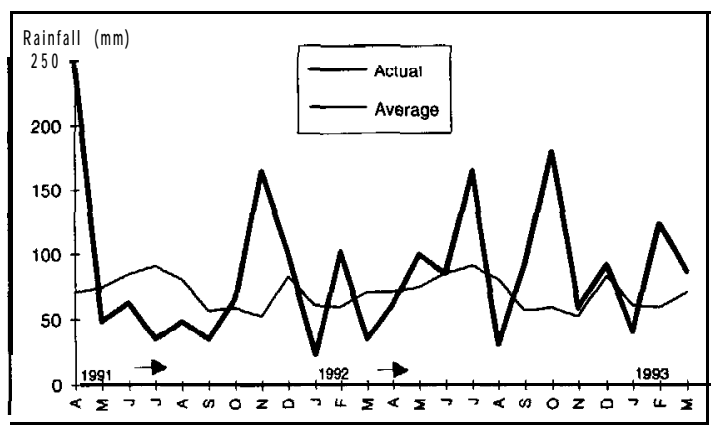

results by sowing early rather than waiting for autumn rains.

Pastures established best when seed was sown at 15 $\mathrm{mm}$ and covered evenly. This could not be achieved on soil that had turf on the surface or was loose or uneven. Generally seedbed preparation was less than ideal, because farmers lacked experience in sowing new pastures.

The 3\% of pastures that failed to establish were sown too deep or too shallow, or damaged by insects.

The cocksfoot content in mixed pastures with tall fescue increased on most sites after estab-lishment (Figure 6). This also occurs in ryegrass and cocksfoot mixtures (Korte et al. 1992). This was more evident when Wana was used. Cocksfoot was sown at $3-4 \mathrm{~kg} /$ ha and tall fescue at $14-17 \mathrm{~kg} / \mathrm{ha}$. Grassline ${ }^{\circledR}$ recommendations are now for $1-2 \mathrm{~kg} / \mathrm{ha}$ cocksfoot (Kara or Saborto) when sown with tall fescue at 18-20 $\mathrm{kg} / \mathrm{ha}$, to reduce chances of cocksfoot dominance (Moloney 1993). Cocksfoot dominance is not desirable in pastures used to finish lambs, as the palatability and seed value of cocksfoot is lower than tall fescue. On sites for stock finishing, cocksfoot could be excluded from the mix. 
At the beginning of the programme the main benefits of dryland species promoted were tolerance to and recovery from drought. However, the main benefit farmers reported back was improved stock growth rates. Growth rates in lambs were recorded at over $300 \mathrm{~g}$ liveweight/day on chicory and up to 250 on tall fescue, compared with usual figures of $100-150$ on resident pastures, and 160 on high-endophyte ryegrass (MacFarlane 1990). Maximum cattle growth rates were recorded at $1.5 \mathrm{~kg} /$ day on tall fescue in winter, 2.6 in spring, 1.5 in summer and autumn.

Farmers also reported better pasture growth and stock carrying capacities, which was confirmed by the grazing record analysis (Figure 7). The differences in pasture growth between dryland species and ryegrass have been shown in trials to be greater in drier than normal seasons (Hume et al. 1993). Winter production from cocksfoot and phalaris mixed pasture at Taratahi near Masterton, after an autumn drought, was $27 \mathrm{~kg}$ DM/ha/day compared with ryegrass at 7 . This highlighted the ability of'dryland grass species to recover quickly from drought. The only problem mentioned by farmers was bloat on some paddocks sown in tall fescue and red clover, owing to the higher clover content in pastures compared with ryegrass (Smith et al. 1993).

Most farmers involved in the programme have confidence in the cost effectiveness of establishing dryland pastures. Some farmers reported full costs could be recovered with just 100 days of grazing, and one farmer reported generating over $\$ 1000 / \mathrm{ha}$ in one season from finishing lambs on chicory. Farmers are generally convinced of the benefits, despite not having gone through a dry summer or autumn when the advantages to dryland species would be greater (Hume et al. 1993).

Dryland species can be established by either cultivating seedbeds, direct drilling, or oversowing onto hill country. Species such as tall fescue and grazing brome (Bromus stamineus) did not persist well on steep hill country. The authors' view on appropriate techniques is that flat to gently rolling country can be cultivated or direct drilled, rolling country prone to soil erosion should be direct drilled, medium hill country can be oversown, but good results are unlikely on steep hills. It is more cost effective to renovate flat to rolling country with a good soil fertility, than to oversow hill country. Despite hill country pasture production being increased by up to $300 \%$, the costs are at least as high as renovating flatter country. However, some farms have no cultivatable land, and it may be justified to establish dryland pasture species on hills to overcome problems the farm may have with poor stock growth rates, ryegrass staggers, drought recovery, and stock carrying capacity.
At the first field days, DSIR staff had to speak at great length to try to convince farmers of the benefits, but at more recent field days farmers have done most of the talking about the good results they are having, and discussion has been on how to use the species rather than whether to use them. The attitude of of some MAF consultants and research staff has also become more positive.

Farmer grazing management of dryland pastures has improved during the programme. It is now widely known that tall fescue pastures need to be closely grazed from August to November to prevent seed head appearance, and after this control, seed head appearance is minimal compared with ryegrass. In the early stages of the programme some farmers ran into early-summer palatability problems on tall fescue when it had not been controlled in early spring.

Some farmers were concerned with seed stem development in chicory and its effects on plant and animal performance. Farmers have reduced stem production with well-timed hard grazings $(0 \mathrm{~cm}$ residual in October and again in early November, at the first sign of stem elongation, followed by grazing plants before they reach $20 \mathrm{~cm}$ in height (Moloney \& Milne 1993).

In the Gisborne region, chicory has created more interest than other species as most farms have a small area of land able to be cultivated, and early stands were very successful.

\section{ACKNOWLEDGMENTS}

B.M. Butler for analysis of grazing records; D.R. Smith for access to tiller core data.

\section{REFERENCES}

Charlton, J.F.L; Hampton, J.G.; Scott,D.J. 1986. Temperature effects on germination of New Zealand herbage grasses. Proceedings of the New Zealand Grassland Association 47: 165-172.

Korte, C.J.; Smith, D.R.; Slay, M.W.A.; Gray, M.H.; Quilter, S.J. 1992. Summary report for farmers on a survey of East Coast drought tolerant pastures. AgResearch Hawkes Bay.

Hume, D.E.; Hay, R.J.M.; Lyons, T.B. 1993. Herbage and animal production from tall fescue and ryegrass based pastures in a summer dry environment. Proceedings of the XVII Inter-national Grassland Congress: 1322- 1323.

MacFarlane, A.W. 1990. Field experience with new pasture cultivars in Canterbury. Proceedings of the New Zealand Grassland Association 52: 139-143.

Milne, G.D.; Fraser, T.J. 1990. Establishment of 1600 
hectares in dryland species around Oamaru/Timaru. Proceedings of the New Zealand Grassland Association 52: 133-137.

Moloney, S.C. 1993. The selection of cocksfoot cultivars and their use in North Island pastoral farming. Proceedings of the New Zealand Grassland Association 5.5: (this volume).

Moloney, S.C.; Milne, G.D. 1993. The establishment and management of Grasslands Puna chicory in farming systems. Proceedings of the New Zealand Grassland Association 55: (this volume)

Smith, D.R.; Slay, M.W.A.; Gray, M.H.; Milne, G.D. 1993. On-farm establishment of drought-tolerant pastures on the east coast of the North Island. Proceedings of the New Zealand Grassland Association 55: (this volume). 